DOI: $\underline{\text { https://doi.org/10.24867/13CG02Kapetanovic }}$

\title{
PROCENA STANJA, REVITALIZACIJA I ENERGETSKA OBNOVA VILE "ANKICA" U BANJI KOVILJAČI
}

\section{ASSESSMENT, REVITALIZATION AND ENERGY EFFICIENT RENOVATION OF VILLA “ANKICA" IN BANJA KOVILJACA}

\author{
Tatjana Kapetanović, Fakultet tehničkih nauka, Novi Sad
}

\begin{abstract}
Oblast - GRAĐEVINARSTVO
Kratak sadržaj - Sadržinu rada čine dve makroceline: teorijski i praktični deo. Prvu celinu čini teorijski deo koji se bavi potpornim zidova, njihovom istorijom, primenom, podelama, principima projektovanja i gradnje. Drugi deo, odnosno praktični deo, prikazuje analizu objekta vila "Ankica" kroz sledeće aspekte: 1) Istorijski osvrt na objekat, kao i detaljan tehnički opis objekta 2) Procenu stanja objekta na osnovu detaljnih vizuelnih pregleda 3)Elaborat energetske efikasnosti objekta sa ocenom razreda energetske efikasnosti 4) Mere sanacije objekta, kako konstruktivne tako i nekontruktivne. Predložene mere sanacija imaju za cilj produžetak $i$ očuvanje nosivosti, funkcionalnosti i trajnosti objekta, a predložene su u skladu sa pravilima očuvanja objekata spomenika kulture.
\end{abstract}

Ključne reči: Potporni zidovi, procena stanja, energetska efikasnost, mere sanacije zidanih zgrada

Abstract - This paper consists of two macro topics: theoretic and practical part. The theoretical part deals with retaining walls, their history, use, classification and principles of design and construction. The second part is practical one, which concerns with villa "Ankica" through the following aspects: 1) the historical review of the building, and its detailed technical description. 2) Assessment of the condition of building based on detailed visual inspection. 3) Design of energy efficiency of the building 4) Structural and non-structural measures for revitalization of the damaged elements of bearing structure and elements of thermal envelope, too. The main purposes of suggested measures are the recovery of bearing load capacity, functionality and durability. All proposed measures were selected in accordance with the regulations for preservation of facilities of cultural heritages.

Keywords: Retaining walls, assessment of structure, energy efficiency, measures for revitalizazion of the masonry buildings

\section{UVOD}

Kod objekata kulturne baštine neophodno je usaglasiti stroge konzervatorske uslove i savremene propise za nosivost, stabilnost, kao i za energetsku efikasnost konstrukcija.

\section{NAPOMENA:}

Ovaj rad proistekao je iz master rada čiji mentor je bila dr Mirjana Malešev, red. prof.
Intervencije na ovakvim objektima podrazumevaju zahvate koji se odnose na promenu ili poboljšanje nosivosti, stabilnosti i trajnosti objekta. Predloženo je rešenje sanacije zidanog objekta poštujući upravo sve pomenute uslove i tražeći balans između svih njih. Rešenje obuhvata uobičajene sanacione mere, ali i poštuje pravila o očuvanju izgleda i originalnosti zaštićenog spomenika kulture. Takođe, sanaciono rešenje daje i sistem mera kojima se objekat unapređuje za jedan razred energetske efikasnosti. Zadatak stabilizacije tla uzvišenja na kojem se sam objekat nalazi rešen je predlozima dva tipa potpornih konstrukcija, sa proračunskim dokazima prema najnovijim evropskim standardima. Upravo potpornim konstrukcijama se bavi i teorijski deo rada.

\section{POTPORNE KONSTRUKCIJE}

Potporne konstrukcije su građevinski objekti koji se koriste za trajno ili privremeno podupiranje mase zemlje ili drugog materijala kojima nije bilo moguće obezbediti njihov prirodni nagib.

Projektovanjem i izgradnjom potpornih konstrukcija stvaraju se slobodni prostori za gradnju novih građevinskih objekata kao što su objekti visokogradnje, saobraćajnice, zatim se postižu osiguranja kod regulacija vodotoka, osiguranje kosina terena i slično. Osim toga, izvođenje potpornih konstrukcija predstavlja jednu od stalnih mera prilikom sanacije nestabilnih padina terena odnosno prilikom sanacije klizišta.

Podela potpornih konstrukcija prema načinu gradnje:

- Zasipne potporne konstrukcije

- Ugradne potporne konstrukcije

- Specijalne potporne konstrukcije

\subsection{Zasipne potporne konstrukcije}

Zasipne potporne konstrukcije se mogu graditi samo ako u fazi njihove gradnje postoji slobodan prostor, odnosno ukoliko tlo ne vrši pritisak na njih. U ovu grupu spadaju različite vrste potpornih zidova: masivni potporni zidovi, olakšani potporni zidovi, ugaoni AB potporni zidovi, potporne konstrukcije od armiranog tla. Posle završetka, ili tokom izgradnje, vrši se zasipanje njihovog zaleđa zemljanim materijalom, pa su po tome ove konstrukcije i dobile ime.

Masivni potporni zidovi vlastitom težinom savladavaju uticaj bočnih opterećenja. Ovo su najstarije vrste potpornih zidova. Često se mogu naći kao delovi odbrambenih zidova u srednjovekovnim gradovima. Svima je zajednička velika težina, kojom se odupiru delovanju pritiska tla u zaleđu (Slika1). 
To naravno zahteva i relativno veliku širinu pa zauzimaju mnogo prostora. Iz tih razloga, a razvojem novih tehnologija, naročito armiranog betona, njihova primena se smanjuje.

Masivni potporni zidovi se najčešće izvode od betona, kamenih blokova (danas retko), raznih prefabrikovanih betonskih elemenata, gabiona i raznih montažnih elemenata koji se pune kamenom, šljunkom i slično.
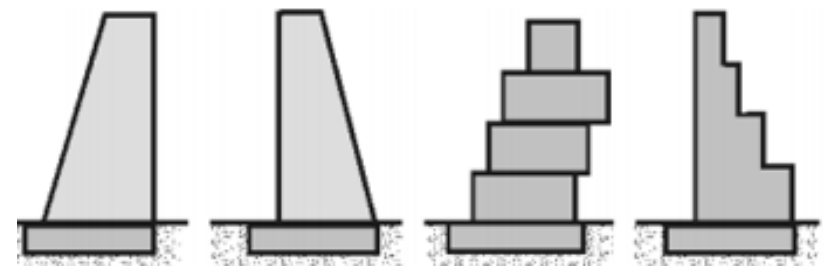

Slika 1. Nekoliko oblika masivnih gravitacijkih potpornih zidova

Kada masivni potporni zidovi pređu određenu visinu postaju preglomazni. Zbog velike težine dolazi do prekoračenja nosivosti ili velikog sleganja temelja na spoljašnjoj strani zida, što menja geometriju i može dovesti do prevrtanja zida. Tada se moraju primeniti određeni konstruktivni zahvati kako bi se zidovi olakšali. $\mathrm{Na}$ taj način nastaju olakšani potporni zidovi. Kako je uglavnom teže zadovoljiti klizanje zida nego prevrtanje, to je ideja olakšanja zida išla $u$ tom smeru. Zid $s$ konzolom, prikladnim oblikovanjem smanjuje ukupni horizontalni pritisak i nešto povećava ukupnu težinu, ali s pravilnijom raspodelom kontaktnih napona. Zid sa zategom, putem zatežućih sila u zatezi uvlači $u$ konstrukciju dodatno horizontalno naprezanje smera obrnutog od pritiska tla i time uravnotežuje sistem $\mathrm{u}$ horizontalnom smeru, tj. na klizanje.

Ugaoni potporni zidovi se uglavnom uvek izvode kao samostalni potporni zidovi, najčešće za pridržavanje nasipa. U pojedinim slučajevima oni nose vertikalna opterećenja. To je slučaj kada tankozidni potporni zidovi služe kao stubovi upornjaka mostova, ili kada su delovi podzemnih prostorija zgrada. Vertikalna opterećenja doprinose njihovoj stabilnosti, ali ne uvek i nosivosti.

Potporni zidovi od armiranog tla javljaju se šesdesetih godina XX veka u Francuskoj kada ih je prvi put primenio Vidal i od tada su u stalnoj ekspanziji. U stručnoj literaturi se nazivaju zidovima od mehanički stabilizovanog tla - MST, (Mechanically Stabilized Earth (MSE) Walls). Sastoje se od spoljne obloge i armature koja se ugrađuje u nasipano tlo iza obloge. Pritisci tla koji opterećuju oblogu se putem zatezanja armature prenose $u$ stabilno tlo iza zida. Pri tome se transfer opterećenja sa armature na tlo ostvaruje putem trenja na njihovom kontaktu. Na taj način se dobija fleksibilan potporni zid gravitacionog tipa.

\subsection{Drenažne mere kod potpornih zidova}

Projektovanje i pravilno izvođenje drenaža iza potpornih konstrukcija od posebnog je značaja kod masivnih betonskih $\mathrm{i}$ armirano betonskih potpornih zidova, dok kod gabionskih zidova i potpornih zidova od montažnih elemenata nisu potrebne posebne mere za rešavanje odvodnje vode koja se nalazi iza zida, jer su ove konstrukcije same po sebi propusne. Naime, masivni odnosno gravitacioni betonski i armirano betonski potporni zidovi veoma slabo propuštaju vodu koja se skuplja iza zida te time sprečavaju njeno proticanje kroz tlo. Za vreme dugotrajnih i jakih kiša nivo podzemne vode može porasti i time dodatno opteretiti ili čak preopteretiti potporni zid, pa se zbog toga drenažom mora sprečiti povećanje hidrostatičkog pritiska na potporni zid.

Osnovni zadatak drenaže je da sprovede podzemnu vodu od slabo propusne sredine odnosno prirodnog tla $u$ pozadini potpornog zida do jako propusne drenažne cevi. Pri tome može doći do ispiranja čestica tla, a da bi se to sprečilo potrebno je drenažu projektovati i izgraditi u slojevima koji imaju krupnoću zrna između početnog prirodnog tla i perforacija na drenažnoj cevi. Svaki sledeći sloj je krupniji od prethodnog tako da je onaj sloj iz kog voda teče tzv. osnova dok je onaj sloj u koga voda utiče tzv. filter.

Filter mora zadovoljiti dva osnovna zahteva, i to hidrauličku i mehaničku stabilnost, čime je definisano filtersko pravilo prikazano na Slici 2.

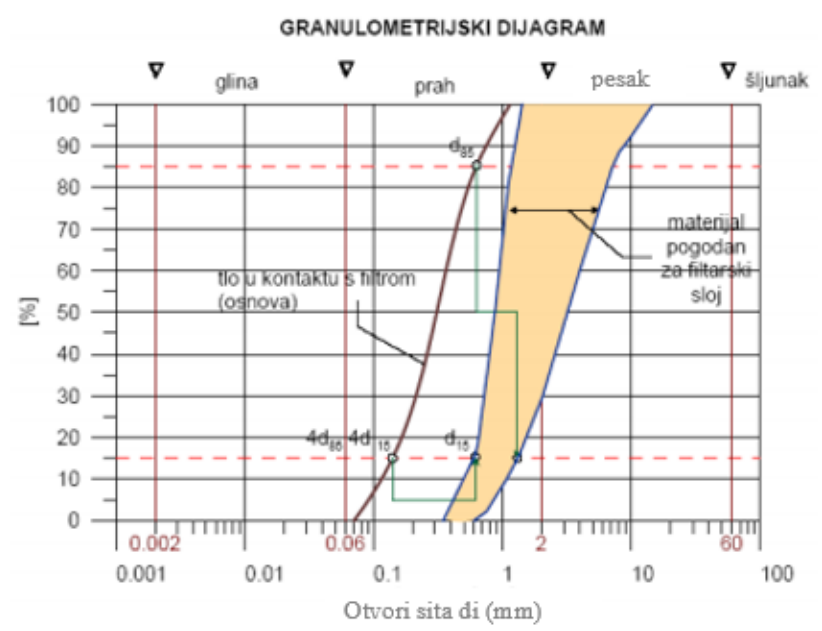

Slika 2. Određivanje osobina filtera na osnovu filterskog pravila

\section{PROCENA STANJA OBJEKTA}

\subsection{Tehnički opis}

Vila je spratnosti $\mathrm{P}+1$ sa bruto površinom prizemlja od $183 \mathrm{~m}^{2}$ i bruto površinom sprata $179 \mathrm{~m}^{2}$. Objekat se nalazi na uzvišenju, koje je osigurano betonskim potpornim zidom. Vila ima približno kvadratnu osnovu dimenzija 13,33 x 12,95 m, sa cilindričnim dodatkom celom visinom objekta na jugoistočnom delu fasade, spoljašnjeg prečnika $2,25 \mathrm{~m}$.

Vila je izgrađena u masivnom zidanom konstruktivnom sistemu, sa nosećim zidovima od opeke u poprečnom pravcu i „mekom“ drvenom tavanicom (Slika 3).

Temelji objekta su trakasti zidani temelji od kamena, ispod svih zidova prizemlja.

Svi zidovi zidani su opekom. Noseći zidovi su debljine 38 cm, tj. zidani „na jednu i po opeku“. Pregradni, nenoseći zidovi izvedeni su debljine $12 \mathrm{~cm}$, tj. na ,pola opeke“.

Međuspratne konstrukcije su drvene. Drvene grede visine $16 \mathrm{~cm}$ se oslanjaju na noseće zidove. Konstrukcija je podaščana sa obe strane.

Objekat je pokriven drvenom krovnom konstrukcijom. Građa je tesana. Konstukcija je na principu stolica, dosta složena zbog oblika krova. 
Svi rogovi se oslanjaju na neke vrste podvlaka - rožnjača, koje zatim opterećenje prenose stubovima, koji su oslonjeni direktno na zidane noseće zidove.

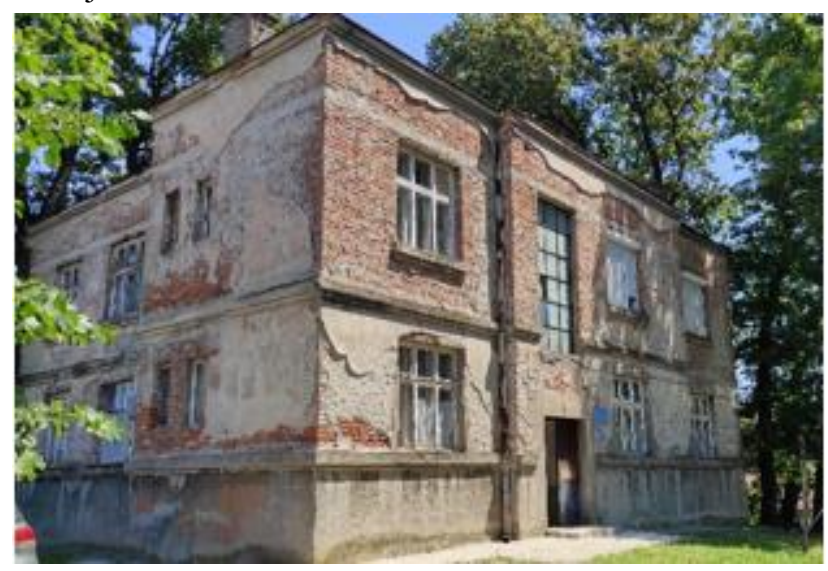

Slika 3. Izgled objekta

\subsection{Procena stanja objekta}

Prilikom procene stanja objekta obavljen je vizuelni pregled spoljašnjeg dela konstrukcije, kao i pregled dostupnih unutršnjih prostorija. Provera geometrije Vile „Ankica“ je urađena merenjem visine i dimenzija $u$ osnovi, kao i utvrđivanjem dimenzija svih elemenata konstrukcije. Urađen je detaljan vizuelni pregled gde je uključeno snimanje položaja i veličine oštećenja. Oštećenja su zabeležena fotografijama.

Većina pukotina i oštećenja ne narušavaju nosivost konstrukcije. Nakvašeni ugao objekta (vlagom sa krova) izazvao je truljenje oslonačkih zona drvenih greda tavanice i delimično smanjio njenu nosivost. Na krovnoj konstrukciji su odrađene mere ojačanja u relativno skorijem periodu. Sanacione mere se mogu smatrati zadovoljavajućim tako da ni njena nosivost, kao ni stabilnost nisu ugroženea.

Najveća oštećenja na objektu jesu pukotine na cilindru koje prolaze kroz celu debljinu zida i mogu se videti i sa unutrašnje strane. Uzroci ovih pukotina ne mogu se odvojeno klasifikovati. Oni predstavljaju simbiozu spoljašnjih uticaja, sleganja tla i nivoa vlage u materijalu (Slika 4).

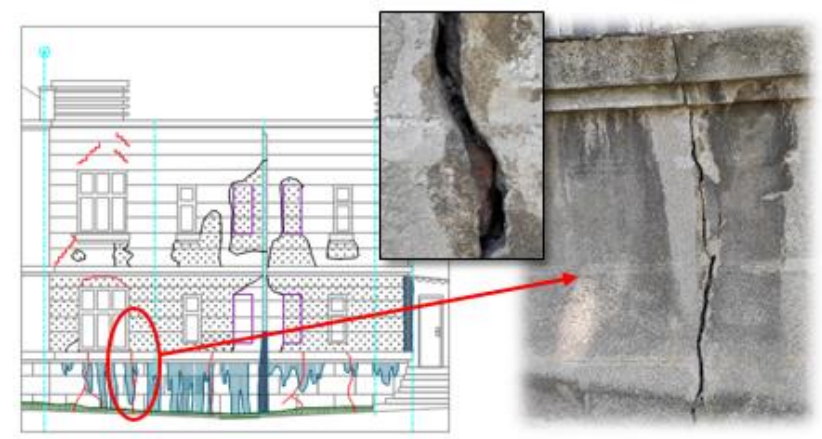

Slika 4. Vertikalna pukotina na cilindru

Vidni su tragovi erozije tla i pokretanja kosine prema ulici na mestu nedostatka potpornog zida, što je izazvalo lokalno narušavanje stabilnosti objekta.

Funkcionalnost objekta svakako jeste narušena. Vlaga u zidovima narušava kvalitet života stanara. Osim činjenice da život u vlažnom prostoru nije nimalo prijatan, on nije ni zdrav. Sem vlage, funkciju narušava i dotrajala spoljašnja stolarija. Pomenuta drvena tavanica sa delimično smanjenom nosivošću ima i povećane ugibe, koji takođe utiču i na smanjenje funkcionalnosti.

Na osnovu stepena oštećenja zidova, trajnost objekta se može smatrati narušenom. Objekat je prepušten sam sebi i zubu vremena i očigledan je nemar prema istom.

\section{ELABORAT ENERGETSKE EFIKASNOSTI}

\subsection{Građevinska fizika}

Pri proračunu energetske efikasnosti urađen je kompletan proračun prolaza toplote kroz građevinske elemente koji čine termički omotač objekta, proračun difuzije vodene pare, proračun gubitaka i dobitaka toplote, i na kraju proračun godišnje potrebne finalne energije za grejanje. Ovim proračunom je zaključeno da je postojeći objekat trenutno energetskog razreda $\mathrm{G}$ i da ne zadovoljava energetske zahteve za postojeće objekte prema Pravilniku o energetskoj efikasnosti zgrada.

U Tabeli 1. dat je pregled koeficijenata prolaza toplote kroz termički omotač objekta pre energetske sanacije.

Tabela 1. Koeficijent prolaza toplote

\begin{tabular}{|l|l|c|c|c|}
\hline \multicolumn{1}{|c|}{ ELEMENT } & POZICIJA & $U\left(W / \mathrm{m}^{2} K\right)$ & $U_{\max }\left(W / \mathrm{m}^{2} \mathrm{~K}\right)$ & $\begin{array}{c}\text { USLOV } \\
\text { ZADOVOLJEN }\end{array}$ \\
\hline Spoljni zidovi & POS SZ1 & 1.261 & 0.40 & $\mathrm{NE}$ \\
\hline $\begin{array}{l}\text { Zidovi ka } \\
\text { negrejanom prostoru }\end{array}$ & POS UZ1 & 1.095 & 0.55 & $\mathrm{NE}$ \\
\cline { 2 - 5 } & POS UZ2 & 1.975 & 0.55 & $\mathrm{NE}$ \\
\hline \multirow{2}{*}{$\begin{array}{l}\text { MK ka ngrejanom } \\
\text { prostoru }\end{array}$} & POS MK1 & 2.080 & 0.40 & $\mathrm{NE}$ \\
\cline { 2 - 5 } & POS PNT & 0.790 & 0.40 & $\mathrm{NE}$ \\
\hline \multirow{3}{*}{ Prozori } & POS PR1 & 3.500 & 1.50 & $\mathrm{NE}$ \\
\cline { 2 - 5 } & POS PR2 & 3.500 & 1.50 & $\mathrm{NE}$ \\
\cline { 2 - 5 } & POS PR3 & 3.872 & 1.50 & $\mathrm{NE}$ \\
\hline \multirow{2}{*}{ Vrata } & POS BV & 3.500 & 1.50 & $\mathrm{NE}$ \\
\cline { 2 - 5 } & POS V & 1.700 & 1.50 & $\mathrm{NE}$ \\
\hline
\end{tabular}

\subsection{Mere za unapređenje energetske efikasnosti}

Proračunom energetske efikasnosti predmetnog objekta, prema odredbama Pravilnika o energetskoj efikasnosti, zaključeno je da pripada razredu G. U cilju poboljšanja energetskih svojstava objekta predviđena je energetska sanacija.

Pošto su prozori na objektu dotrajali, potrebna je njihova zamena. Merama tehničke zaštite objekta se insistira na očuvanju izvornog izgleda, spoljašnje arhitekture i enterijera. Kako bi se postigla bolja energetsku efikasnost objekta, predviđena je zamena novim drvenim prozorima (prozor krilo na krilo) identičnog rama, s tim da staklo na spoljašnjem krilu ostaje jednostruko, dok se za staklo na unutrašnjem krilu uzima kao dvostruko. Time se dobijaju manji toplotni gubici, a isti toplotni dobici objekta.

$\mathrm{Za}$ potrebe unapređenja energetske efikasnosti međuspratne konstrukcije ka negrejanom prostoru, predlaže se korišćenje termoizolacija od meke kamene vune "Knauf NaturBoard FIT". Debljina izolacionog sloja ograničena je visinom nosivih greda $i$ uzima se na maksimalnu debljinu $16 \mathrm{~cm}$.

Nakon uvođenja predloženih mera za termičku sanaciju i ponovnog proračuna energetske efikasnosti, potreba za energijom na godišnjem nivou sa značajno smanjila. Energetski razred se popravio i sada objekat pripada $\mathrm{F}$ razredu. Objekat sada zadovoljava uslove po pitanju energetske efikasnosti u skladu sa Pravilnikom o energetskoj efikasnosti (Sl. glasnik RS br.061/2011). 
Na Slici 5 prikazan je dijagram potrebne energije u $\mathrm{kWh}$ za grejanje po mesecima nakon energetske sanacije.

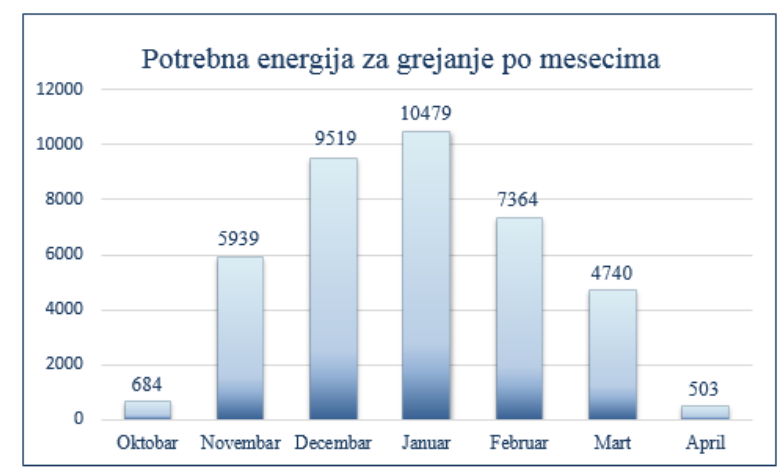

Slika 5. Dijagram potrebne energije $u \mathrm{kWh}$ za grejanje po mesecima nakon izvršene sanacije

\section{MERE ZA REVITALIZACIJU OBJEKTA}

Nakon detaljne procene stanja i uvida u mere tehničke zaštite, predložene su mere sanacije objekta, koje obuhvataju postupak konzervacije.

\subsection{Konstrukcijske mere sanacije}

- Izrada potporne konstrukcije

Kako bi se sprečio dalji gubitak lokalne stabilnosti objekta predložena su dva rešenja potporne konstrukcije u jugoistočnom delu dvorišta: ugaoni armirano betonski potporni zid ili potporna konsrukcija od gabiona.

- Sanacija oslonačkih zona nosećih elemenata međuspratne konstrukcije

Metoda sanacije ovog oštećenja podrazumeva privremeno podupiranje konstrukcije, isecanje oštećenog mesta, dodavanje novog oslonačkog dela adekvatno zaštićenog na kraju. Povezivanje se može sprovesti tradicionalnim vezama ili međusobnim lepljenjem dva dela, uz ojačanje šipkama od čelika ili fiberglasa.

- Postavljanje nadprozornih greda

Na mestima gde su nadprozornici izvedeni kao nepravilni zidani lukovi i gde su izvedeni u vidu zidanog zida predlaže se izbijanje dela zida iznad otvora i ubacivanje prefabrikovanog nadprozornika.

Kod otvora iznad kojih je nadprozornik izveden u vidu horizontalnog serklaža, ukloniće se deo serklaža iznad otvora i betoniraće se novi serklaž i nadprozornik na tom mestu prema datom tehničkom rešenju.

- Sanacija pukotina u sokli fasade

Predlog saniranja pukotina čija širina ne prelazi $10 \mathrm{~mm}$ jeste injektiranje masama na bazi cementa.

U cilindričnom delu konstrukcije postoje pukotine koje su veće od $10 \mathrm{~mm}$. Predlog sanacije ovih pukotina jeste njihovo premošćavanje FRP (Fiber Reinforced Polymer) materijalima. Predviđeno je postavljanje karbonskih traka duž celog obima cilindričnog dela konstrukcije, kako bi se sanirale pukotine i učvrstila konstrukcija.

\subsection{Nekonstruktivne mere sanacije}

- Izrada horizontalne hidroizolacije

- Sanacija fasade (uklanjanje preostalog trošnog maltera sa fasade, čišćenje malterskih spojnica, isušivanje zidova i zamena novim malterom, zamena celokupne sokle fasade, popravka uske profilacije na istočnoj fasadi, izrada nove malterske plastike).
- Izvođenje ili zamena podova u svim prostorijama objekta.

- Uklanjanje - struganje oštećenog dekorativnog premaza sa unutrašnjih površina zidova, priprema zidova i nanošenje nove boje $u$ dogovoru sa predstavnicima nadležnog Zavoda za zaštitu spomenika kulture.

- Zamena odvojenog i ispucalog štukatura (maltera na trščanoj podlozi) u pojedinim prostorijama i izrada novog prema detaljima urađenim u dogovoru sa predstavnicima nadležnog Zavoda za zaštitu spomenika culture.

- Zamena opšivki i svih olučnih instalacija.

\section{LITERATURA}

[1] Inženjerska komora Srbije: Pravilnik o energetskoj efikasnosti zgrada,"Sl.glasnik RS", br. 61/2011, Beograd

[2] Malešev M., Radonjanin V.: Trajnost i procena stanja betonskih konstrukcija, Skripta sa predavanja, Fakultet tehničkih nauka, Novi Sad

[3] V. Radonjanin, M. Malešev, T. Kočetov-Mišulić, R. Lekić: Materijal sa predavanja iz predmeta Oštećenja i sanacije drvenih, čeličnih i zidanih konstrukcija, Fakultet tehničkih nauka, Novi Sad

[4] Amir Čaušević, Nerman Rustempašić: Rekonstrukcije zidanih objekata visokogradnje, Sarajevo

[5] Zgradarstvo, skripta, prof. dr Slavka Stankovića, Arhitektonsko- građevinski fakultet u Banja Luci

[6] Opštinski Zavod za zaštitu spomenika kulture Valjevo, Tehnička dokumentacija vile "Ankica“"

[7] EN 1990 : 2002 - Evrokod 0 „Osnove proračuna konstrukcije“; Beograd, februar 2006

[8] EN 1991-1-1:2002 - Evrokod 1 „Dejstva na konstrukcije“; Beograd, novembar 2009

[9] EN 1991-1-3:2003 - Evrokod 1 „Dejstva na konstrukcije“; Beograd, novembar 2009

[10] EN 1991-1-4:2005 - Evrokod 1 „Dejstva na konstrukcije"; Beograd, novembar 2009

[11] EN 1992-1-1:2004 - Evrokod 2 „Proračun betonskih konstrukcija“; Beograd, februar 2006

[12] EN 1997-1:2004 - Evrokod 7 „Geotehnički proračun“; Beograd, novembar 2009

[13] Zoran Brujić: „Betonske konstrukcije u zgradarstvu (prema Evrokodu)“", Novi Sad

[14] Z. Bonić: Potporne konstrukcije, Niš

[15] N. Suljić: Potporne konstrukcije prema Evrokodu, Beograd 2018

[16] Rešenja i proizvodi KnaufInsulation: www.knaufinsulation.rs

\section{Kratka biografija:}

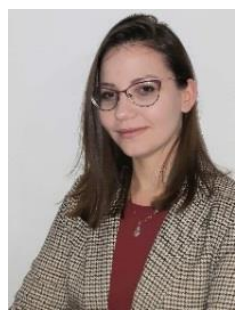

Tatjana Kapetanović rođena je u Loznici, 1994. godine. Osnovne akademske studije završila je na Fakultetu tehničkih nauka 2018. godine, iz oblasti građevinarstvo - konstruktivni smer. Master akadamske studije smer - konstrukcije upisala je iste godine. Master rad iz oblasti Sanacija drvenih, čeličnih i zidanih konstrukcija uradila je i odbranila 2020. godine. 